\title{
UBER PRICE DISTRIBUTION AS A MEASURE OF ACCESSIBILITY: AN EXPLORATORY ANALYSIS IN THE CITY OF SÃO PAULO
}

\author{
Liliane Matias de Almeida ${ }^{1}$, Andre Insardi ${ }^{1}$, Suzane Strehlau $^{1}$ and Eduardo de Rezende Francisco ${ }^{2}$ \\ ${ }^{I}$ ESPM; ${ }^{2} F G V$, Brazil
}

\begin{abstract}
The purpose of this paper is to understand if the estimated price for using the UBER application service can be used as a socioeconomic indicator to measure accessibility. New personal transport services such as UBER gain space in the shared economy and spread quickly around the world, creating a new way of transporting people. The distribution of transportation app fleets has been used to explain the socioeconomic distribution of various locations. Wang \& Um (2018) enriched the accessibility study by analyzing UBER application utilization in the Atlanta (USA) region, using wait time as a socioeconomic indicator for accessibility. This study will analyze the price applied to use UBER service in the city of São Paulo, as an indicator of accessibility. Approximately 2.2 million price samples per service were collected, and exploratory analysis with quantitative approach through regression was performed.
\end{abstract}

\section{KEYWORDS}

Big Data, Mobility, Accessibility

\section{INTRODUCTION}

Big Data has built a wealth of information that can complement many traditional ways of analyzing data. Much more than contributing to data analysis, it enables new ways to collect data and turn it into compelling data to generate results. The Big Data build carries a feature called the three Cs, which consists of small, scattered data, data capacity, and data community. These concepts have encouraged data owners to open their foundations to be explored by new forms of analysis. Not just data, but Big Data allows new data about people, behaviors and beliefs (Letouzé \& Jütting, 2014). The new context of shared economy has produced data that may complement the analysis of many studies, for example the use of the UBER application service in accessibility studies.

Studies and researches on accessibility present socioeconomic indicators such as economic development, means of transport and opportunities offered, as well as the demographic, social, economic and cultural constraints of a region. Even with the availability of data available through these indicators, Wang and $\mathrm{Mu}$ (2018) identified waiting time as a socioeconomic indicator, able to contribute to accessibility studies, in contrast Páez, Scott and Morency (2012) put the travel cost as a positivist measure of accessibility, this context inspires us to use the estimated price of Uber travel as a potential mediated accessibility.

The main objective of this paper is to understand if the price applied to the distribution of UBER application fleet in the city of São Paulo can be considered as an indicator of accessibility. With a quantitative methodology, the collected data will go through regression analysis to assess the relationship between the price practiced by Uber versus socioeconomic indicators such as income, population density, bus stop distribution and others.

The research results will contribute to the academic field under study on mobility, in addition to understanding price as an indicator of accessibility.

\section{THEORETICAL RATIONALE}

When collecting data for statistical inference, much information was considered useless because it could not be analyzed by standard procedures, this considerable amount of data was called Big Data. Big Data plays an important role in contributing and producing indicators to improve policies and processes. It offers a possibility 
for simplified data analysis, complementary to traditional statistical data, especially in developing countries. Data production continues to expand, and new forms of data analysis are needed for useful use and application. A highlight of the use of Big Data is the companies' dissatisfaction with the use of official data and how the analyzes are performed (Letouzé, \& Jütting, 2014).

Data production exceeds old standards and with the new shared economy, the contribution to data production is positive. There are many ways to negotiate and to facilitate, applications that simplify and mediate between consumer and supplier are present worldwide. These new ways of negotiating, we find the shared economy, which emerged in the United States in the 1990s, having as its main driver the technology (Silveira; Petrini; Santos. 2016). The authors emphasized the ability to access products and services without the need for purchase and without the need for intermediaries. According to Bostman and Rogers (2009), the shared economy meets the needs more economically for individuals through loan, rent or exchange. An example is the UBER application, officially created in 2010 in San Francisco, California - USA, the company was valued at 69 billion (ECONOMIA, 2017). Aiming to transform urban mobility, the app connects users and drivers today in more than 600 cities in 65 countries (UBER, 2018).

In 2012, Páez, Scott and Morency, while studying accessibility measures, the authors sought to understand the measures that contribute to accessibility and their importance and contribution to the development of transportation and use by society. The authors' study was important to understand the relevance of accessibility in the daily experience of individuals when performing their activities away from home.

By measuring accessibility through economic indicators, the authors stated that the expansion of the means of transport leads to economic growth and people's socioeconomic mobility (Páez; Scott; Morency. 2012), following this thinking, UBER contributes to studies of transport, enabling and facilitating the activity and mobility of people.

To measure accessibility, there are two elements that must be considered, the cost of travel, considering that there is no standard, but each individual has a particular travel cost, and the amount of opportunity. Points should be considered such as the means of transport available, as well as the origin and destination of the trip, and finally the purpose of the trip (Islam et al., 2008). Páez et al (2012), contributed to accessibility measures based on land use, contributed positivist and normative implementations of various accessibility indicators, such as the amount of services offered in the region, such as supermarket, dentist, laundry, among others. others. Individuals from a certain region, based on these indicators, have normative accessibility, how much the individual must travel to reach the goal, and positivist accessibility, the real willingness to reach the goal, that is, how much they are willing to have access to the service. These indicators are measured by the distance or time traveled to the destination "accessibility is a measure of supply, ie potential mobility is not a behavioral descriptor” (Salomon; Mokhtarian. 1998, p.131).

The Wang and Mu (2018) study, to measure accessibility, reviewed the literature on mobility and transport, and found that the concept of accessibility is associated with autonomy and ease in interacting with activities distributed in the region. While Páez, Scott and Morency, 2012, use the economic development measures, means of transportation and opportunities offered, Miller (2003) pays attention to demographic, social, economic and cultural constraints, but, in both studies, the authors complemented the studies, with travel time as a measure of accessibility. Wang and $\mathrm{Mu}$ then discuss the waiting time and time spent from the origin to the destination of the individual, and made a study, by regressing the data collected from Uber, to use time as a socioeconomic indicator, complementing, circumstance analysis and aspects that affect the community and economy of a region.

Finally, the accessibility literature helps clarify and pose the research question, which is based on the study by Wang and $\mathrm{Mu}$, the estimated price for UBER services as a measure of accessibility:

The estimated price of the trip with Uber as an accessibility.

Hypothesis 1- The estimated price when requesting a trip on the Uber platform can serve as a proxy for an accessibility measure in the city of São Paulo.

Hypothesis 2 - The distribution of the estimated price of Uber is related to the polarization of the socioeconomic indicators of the city of São Paulo. 


\section{METHODOLOGY}

\subsection{Data and Variables}

We accessed the UBER portal (https://developer.uber.com/) and put the price applied to the city of São Paulo, during 30 days of 2018. The available modalities are POOL, UBERX, VIP, SELECT and BLACK, On the UBER platform you can check the approximate price before requesting the service. Below is a map of the region of São Paulo, which has the same tariff application according to the chosen modality.

Currently, the city of São Paulo has 32 regions, with regional prefectures, and these are divided into districts, which in turn are subdivided into sub-districts, popularly called "neighborhoods" by citizens.

The city of São Paulo was considered the 7th largest city in the world in 2016. It is divided into 96 districts, a territorial and administrative division that provides some autonomy in local public administration (Francisco 2010). Following the methodology proposed by Wang \& Mu 2018, districts were used as the unit of analysis of the study collecting the estimated price of Uber. In order to ensure that each district had at least one random sample point and each square kilometer had at least one random sample point, the software developed for data collection followed the following logic:

- $\quad$ Divide the city of São Paulo into 1 square km squares, totaling 1.720 squares;

- Draw a point (to be used as the source of the estimate) at random in each grid;

- With the coordinate drawn consult the Uber API to estimate the price of a fictitious race between the drawn point of origin and the ground zero of the city of São Paulo. (Praça da Sé);

- If the return is successful, save the result;

- If there is an error in the call, make 3 attempts of new calls with the same coordinate; persisting error write attempt as null;

This process was repeated every 30 minutes during the period from August 15 to September 15, 2018. This generated over 2.500.000 Uber API queries, of which over 2.240.000 received a valid response.

To meet the sample collection process, a C\# program was developed following "cloud computing" concepts to access APIs ("Application Programming Interface") provided by Uber. This program was allocated to the Azure "cloud computing" service provided by Microsoft.

\subsubsection{Socioeconomic Data}

District-level socioeconomic data were obtained from the IBGE, and more specifically from the 2010 Census universe and sample, from the Ministério do Trabalho e Emprego (Relação Anual de Informações Sociais - RAIS) through the portal Infocidade from the city of São Paulo, from the portal of Indicators of the São Paulo Municipalities of SEADE and from the Geosampa website of the city of São Paulo (http://geosampa.prefeitura.sp.gov.br).

Rais is a governmental labor relations management tool of the Ministry of Labor. The data are compiled from statements completed by the companies themselves about the labor situation of their employees. Statements are required for a number of companies named by law (BRASIL, 2016).

The SEADE Foundation is a nationally recognized statistical institution for its technical expertise and is responsible for producing and aggregating existing data in the interest of the State of São Paulo and its municipalities (Francisco, 2010). São Paulo City's GEOSAMPA online platform provides a series of georeferenced data, including data from the municipal service system such as bus stops.

All data were fetched or aggregated at district level (Wang \& Mu 2018, Francisco 2010). The 2010 Census sample was used to calculate the percentage of districts within each class of travel time, and the percentage of motorized households in relation to motorcycles and cars. For both household and person sample levels, weights were used to weight the representativeness of inputs for entire districts.

Table 1. Socioeconomic data of the city of São Paulo

\begin{tabular}{lll} 
Data & Source & Data \\
\hline Area $(\mathrm{km} 2)$ & IBGE data. Taken from the indicadores dos municípios paulistas & 2009 \\
& (IMP) SEADE Foundation & \\
& Original IBGE census data, with annual adjustment calculated by & \\
& SEADE Foundation & $2010 / 2018$ \\
Population & Taken from the indicadores dos municípios paulistas (IMP) & \\
Density & SEADE Foundation & $2010 / 2018$
\end{tabular}


Permanent Private Households Per Capita Income - Demographic Census (In current reais)

Jobs (Commerce, Services, Manufacturing Industry, Civil Construction)

Establishments (Commerce, Services, Manufacturing Industry, Civil Construction)

$\%$ non-white (black, brown, indigenous)

Time of travel

Proportion of households with car and motorcycle
Original IBGE census data, with annual adjustment calculated by SEADE Foundation

Taken from the indicadores dos municípios paulistas (IMP) SEADE Foundation

Original data from the IBGE Demographic Census. Taken from the indicadores dos municípios paulistas (IMP) SEADE

Foundation

Portal infocity of the city of São Paulo. Original data source:

Ministério do Trabalho e Emprego. Relação Anual de Informações Sociais - Rais

Portal infocity of the city of São Paulo. Original data source: Ministério do Trabalho e Emprego. Relação Anual de Informações Sociais - Rais

IBGE data. 2010 Census

IBGE Census Sample. The proportion of people, weighted by weight, in each travel time class of the questionnaire, by district IBGE Census Sample. The proportion of motorization by district (of cars and motorcycles) from the sample's heavy households
$2010 / 2018$

2010

$2010 / 2016$

$2010 / 2016$

\subsection{Data Analysis}

While exploring the 2.500 .000 queries performed in the Uber API, two behavioral patterns were noted: the first with the lack of service for some products like Uber Black and the second with the lack of service in certain areas of the city, as we can see in Figure 1. It is possible to notice the absence of attendance in the extreme south and in a strip of the northern part of the city, besides small points scattered throughout the city.

The extreme south is a mangrove area that has no streets to access, while the strip in the northern region of the city and other points without coverage of any product, are regions that Uber qualifies as risk zones, not providing care.

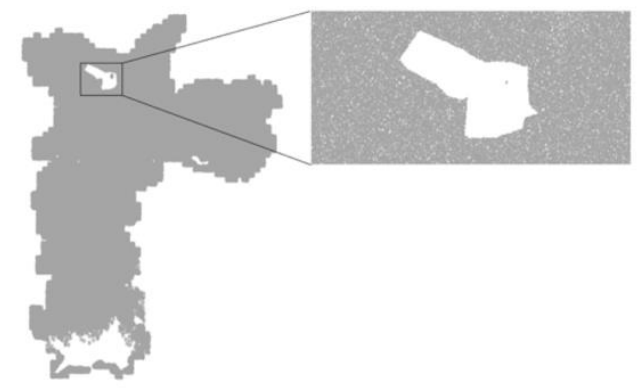

Figure 1. Uber price estimate collection points

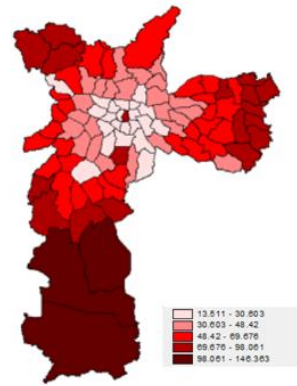

Figure 2. Distribution of fare averages by district

It can be noted that Uber X, Uber's most popular service, has the largest coverage, with almost $100 \%$ of valid time estimation responses. Consequently, it is the service that best demonstrates the distribution of the fleet in space; In order to define an accessibility measure it was considered coherent to adopt Uber X prices for the sequence of analyzes.

By filtering only the Uber $\mathrm{X}$ product data, there is a wide range in averages and deviations between districts, as shown in Figure 2. It is reasonable to assume that a larger, more affordable district has a lower average price estimate. (Wang \& Mu 2018). Therefore, for OLS regressions a model was created having the average of the estimated Uber price as the dependent variable. For continuity after the OLS model we performed the stepwise technique using the software R with the STATS and CAR packages, to verify the geographic dependence of the model we performed the Moran I and created a autoregressive spatial model (SAR) as suggested by Francisco 2010.

\subsubsection{OLS Simple Linear Regression}

From the principle of statistical inference, we can make statements about characteristics of a population in samples of it. Regression analysis is the term that describes a family of methods that allows exploring and inferring the relationship between one or more variables (Francisco 2010, HAIR 2005). 
For the construction of OLS models, we used aggregate data by district of the Uber X product only, having as a dependent variable the average estimated service price for the model. The following independent variables were used:

- $\quad$ area $(\mathrm{km} 2)$,

- Population,

- Population density,

- Number of Permanent Private Households,

- Income per Capita - Demographic Census (In current reais),

- Jobs (Commerce, Services, Manufacturing Industry, Civil Construction),

- Establishments (Commerce, Services, Manufacturing Industry, Civil Construction),

- $\quad$ Percentage of non-white residents (black, brown and indigenous),

- Time of travel

- Proportion of households with car and motorcycle.

- $\quad$ Number of bus stops by district

- Mileage of bus lines by district

- $\quad$ Number of metro stations by district

SAR autoregressive spatial model

Francisco (2010) suggests that before creating an autoregressive spatial model, it is convenient to verify the spatial self-correlation of the dependent variable, for this the literature has a measure consecrated by Moran. The Moran index is an indicator of correlation between the value of the variable observed in a spatial unit of analysis and the values of the same variable in the region.

After verifying the geographic self-correlation of the estimated Uber price through Moran's I, the variables with high significance in the OLS model were selected and an autoregressive spatial model (SAR) was developed, which Francisco 2010 defines as a model of regression capable of incorporating the spatial neighborhood matrix (or spatial proximity) as part of the set of explanatory variables.

To make the geographic regressive model, the software GeoDa version 1.12 was used.

\section{RESULTS}

The table 2 summarizes the results of the OLS model taking as a dependent variable the average of the estimated price of Uber $\mathrm{X}$ for the model. It can be noted that the model containing the average as the dependent variable has a degree of explanation with an R-squared 0.812 .

Table 2

\begin{tabular}{|c|c|c|c|c|c|}
\hline \multirow{2}{*}{ DV } & & \multicolumn{4}{|c|}{ Uber $X$ average } \\
\hline & & \multicolumn{2}{|c|}{ Coefficient } & \multirow{2}{*}{$\frac{\text { std Error }}{217.100}$} & \multirow{2}{*}{$\frac{\text { p-value }}{0,85112}$} \\
\hline (Intercepts) & & - & 40.880 & & \\
\hline QTLINBUS2018 & Number of bus lines & - & 0,6 & 55 & 0,99186 \\
\hline KMLINBUS2018 & $\mathrm{Km}$ of bus lines & - & 7 & 19 & 0,72879 \\
\hline QTPONTBUS2018 & number of bus stops & & 35 & 38 & 0,36675 \\
\hline QTESTMETRO2018 & Number of metro station & - & 625 & 1.509 & 0,68011 \\
\hline RENDP2010 & Per capita income & & 2,3 & 2,98 & 0,43462 \\
\hline ARE1 & Area $(\mathrm{km} 2)$ & & 266 & 89 & 0,00401 \\
\hline POP2018 & Population & - & 0,21 & 0,29 & 0,46074 \\
\hline DENPOP2018 & Population density & - & 0,09 & 0,43 & 0,82841 \\
\hline DOMP2018 & Number of Permanent Private Households & & 0,38 & 0,84 & 0,64869 \\
\hline ESTAB2016 & Establishments & & 1,71 & 2,09 & 0,41734 \\
\hline EMP2016 & Jobs & - & 0,06 & 0,10 & 0,51798 \\
\hline PNBRAN2010 & Percentage of nonwhites & & 130.200 & 22.470 & 0,00000 \\
\hline TEMP2010_5MIN & Travel time to work up to $5 \mathrm{~min}$ & - & 414.300 & 337.200 & 0,22309 \\
\hline
\end{tabular}




\begin{tabular}{|c|c|c|c|c|}
\hline TEMP2010_30MIN & Travel time to work up to $30 \mathrm{~min}$ & 24.240 & 227.300 & 0,91536 \\
\hline TEMP2010_60MIN & Travel time to work up to $60 \mathrm{~min}$ & 240.700 & 240.600 & 0,3203 \\
\hline TEMP2010_120MIN & Travel time to work up to $120 \mathrm{~min}$ & 77.080 & 232.900 & 0,74161 \\
\hline TEMP2010_121MIN & Travel time to work more than $120 \mathrm{~min}$ & 557.500 & 287.200 & 0,05596 \\
\hline TEMP2010_0MIN & Do not travel & 7.120 & 221.300 & 0,97442 \\
\hline PDOMC2010 & Proportion of households with car & 143.400 & 106.400 & 0,18181 \\
\hline PDOMCM2010 & Promotion of car and motorcycle households & 43.360 & 23.840 & 0,07294 \\
\hline
\end{tabular}

An OLS stepwise model was created for the estimated average price, due to its greater explanatory power, in order to find which variables are significantly related to the estimated average price of Uber X. Table 3 shows a high degree of significance for area. district, population density, percentage of non-whites, travel time up to 5 minutes, travel time up to 60 minutes, travel time over 120 minutes, proportion of households with car and proportion of households with a R-squared motorcycle 0.804 .

Table 3

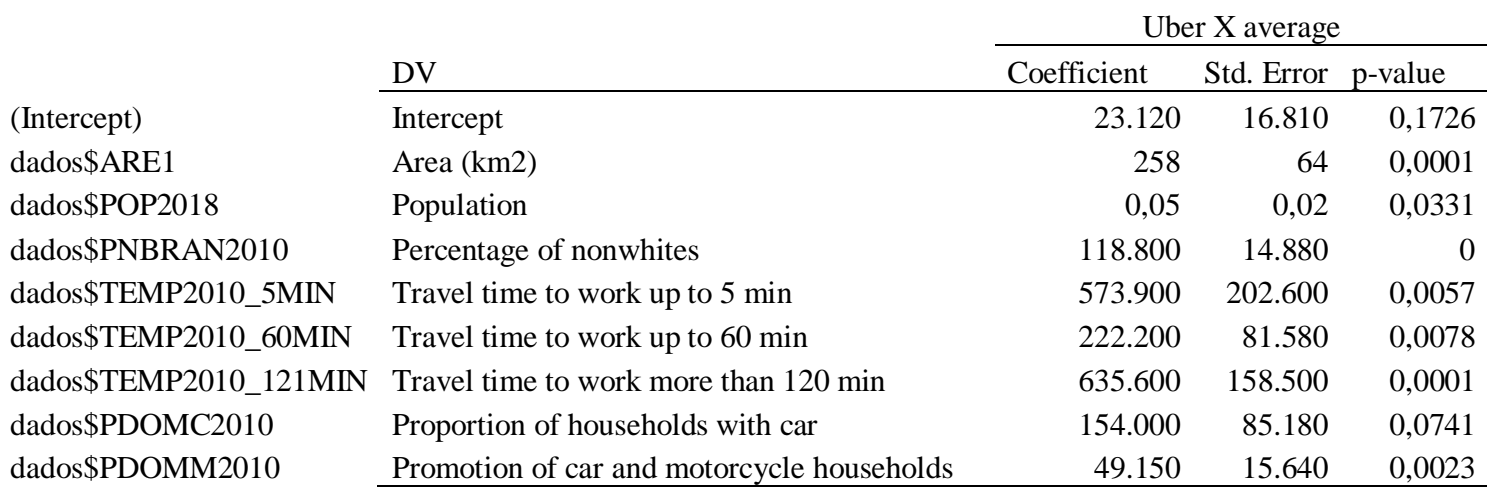

The figure 3 shows the geographical dependence of the estimated average price of Uber X, with a Moran I of 0,67 which shows high geographic dependence of the dependent variable. In Figure 4 we notice the distribution of the variable and its geographic dependence across the neighborhood. We can notice uniform areas with lower attendance cost.

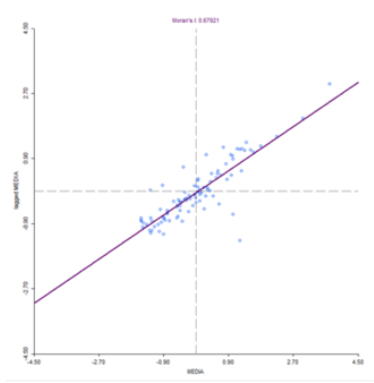

Figure 3. I of Moran average estimated price of Uber X service

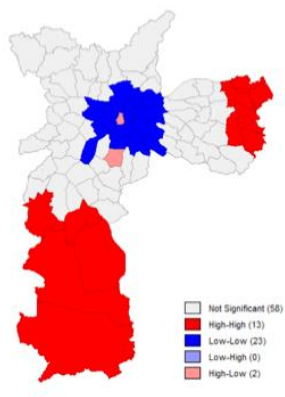

Figure 4. Average neighborhood cluster estimated service price Uber X

From the variables in Table 3 we generate a spatial regression model for the average estimated price of Uber X. The results in Table 4 show a high degree of significance for the variables area, percentage of non-whites, time to work up to $5 \mathrm{~min}$. With the incorporation of the geographical factor in the R-squared model goes to 0,78 . 
Table 4. Spatial regression result for average estimated price Uber $\mathrm{X}$

DV

Uber $\mathrm{X}$ average

\begin{tabular}{llrrr} 
& & Coefficient & Std.Error & p-value \\
\cline { 3 - 5 } W_MEDIA & & 0,43 & 0,096 & 0 \\
CONSTANT & & 14,69 & 6,066 & 0,02 \\
ARE1 & Area $(\mathrm{km} 2)$ & 0,26 & 0,055 & 0 \\
PNBRAN2010 & Percentage of nonwhites & 57,73 & 11,064 & 0 \\
TEMP2010_5MIN & Travel time to work up to 5 min & 364,46 & 171,833 & 0,034 \\
\hline
\end{tabular}

In analyzing the results, we cannot confirm H1, that is, we cannot say that the Uber price estimate can be used as a proxy for accessibility, because for some variables the relationship with the estimated price of Uber $\mathrm{X}$ was not significant.

In contrast, we can confirm $\mathrm{H} 2$ for the distribution of the variables area, population, percentage of non-whites, commute time up to $5 \mathrm{~min}$, commute time up to $60 \mathrm{~min}$, commute time over $120 \mathrm{~min}$, proportion of households with car and proportion of households with car and motorcycle, it is noteworthy that in the study conducted in the city of Atlanta by Wang \& Mu 2018, the relationship between waiting time of care of Uber and the distribution of minorities was not significant, i.e., the change of the dependent variable and the studied city showed a significant variation of the results, this fact motivates us to continue the deepening of the measures made available by Uber and its competitors in order to reach a potential mediated accessibility.

\section{CONCLUSION}

By analyzing the charging methods of Uber from the perspective of accessibility we identified a strong relationship with some socioeconomic variables, although not confirmed $\mathrm{H} 1$, this urges us to seek to understand increasingly the dynamics of these new services.

As one of the main findings of this paper is the relationship between Uber's estimated price and the distribution of the nonwhite percentage variable, the fact that the result of this relationship turned out to be different from that found by Wang \& Mu 2018 in Atlanta from the strength to further investigation. fleet distribution of "crowdsourcing" transport services as an accessibility measure, since minority distribution is significantly associated with accessibility measures (Páez, Scott and Morency 2012).

\section{REFERENCES}

Botsman, R.; Rogers, R. 2009. O que é meu é seu: como o consumo colaborativo vai mudar o nosso mundo. Bookman, Porto Alegre.

Francisco, E. R. 2010. Indicadores de renda baseados em consumo de energia elétrica: abordagens domiciliar e regional na perspectiva da estatística espacial. Tese de Doutorado.

Islam, M. S., Rahaman, K. R., \& Ahmed, S. J. 2008. "Demand of participants" or "supply of opportunities": measuring accessibility of activity places based on time geographic approach. Journal of Urban Planning and Development, 134(4), 159-165.

Letouzé, E.; Jütting, J. 2014. Official statistics, big data and human development: towards a new conceptual and operational approach. Data Pop Alliance and PARIS21.

Wang, M.; Mu, L. 2018. Spatial disparities of Uber accessibility: An exploratory analysis in Atlanta, USA. Computers, Environment and Urban Systems, 67, 169-175.

da Silveira, L. M.; Petrini, M.; dos Santos, A. C. M. Z. 2016. Economia compartilhada e consumo colaborativo: o que estamos pesquisando?. REGE-Revista de Gestão, 23(4), 298-305.

Páez, A.; Scott, D. M.; Morency, C. 2012. Measuring accessibility: positive and normative implementations of various accessibility indicators. Journal of Transport Geography, 25, 141-153.

Salomon, I.; Mokhtarian, P.L. 1998. What happens when mobility-inclined Market segments face accessibility-enhancing policies? Transportation Research Part D-Transport and Environment 3, 129-140 